\title{
Child-rearing experiences of mothers with early adolescents in Korean multicultural families
}

\author{
Sangmi Lee ${ }^{1}$, Hyun Young Koo ${ }^{2}$ \\ ${ }^{1}$ Associate Professor, Department of Nursing, Dongyang University, Yeongju; ${ }^{2}$ Professor, College of Nursing $\cdot$ Research Institute of Nursing Science, Daegu \\ Catholic University, Daegu, Korea
}

Purpose: This study was conducted to explore the child-rearing experiences of mothers with early adolescents in Korean multicultural families. Methods: The participants were six mothers with early adolescents in Korean multicultural families. Data were collected through in-depth interviews. The main question was, "Could you tell me about your child-rearing experiences with your adolescent child?" The data were analyzed using qualitative content analysis. Results: Four categories resulted from the analysis of child-rearing experiences of mothers with early adolescents in Korean multicultural families, as follows: "separation between myself and others", "distance between myself and my adolescent child", "making efforts to bridge the gap between myself and others", and "trying to connect with my adolescent child closely". Conclusion: These findings indicate that mothers in Korean multicultural families made many efforts to bridge the gap between themselves and other people, and tried to connect with their children closely. The findings of this study emphasize specific aspects of how mothers with early adolescents experienced child-rearing in Korean multicultural families.

Key words: Adolescent; Mothers; Family; Cultural diversity

\section{Corresponding author Hyun Young Koo} College of Nursing, Daegu Catholic University, 33 Duryugongwon-ro, 17-gil, Nam-gu, Daegu 42472, Korea

TEL: +82-53-650-4829

FAX: +82-53-650-4392

E-MAIL: hykoo@cu.ac.kr

Received Mar 11, 2021

Revised Apr 3, 2021

Accepted Apr 4, 2021

\section{INTRODUCTION}

\section{Background}

International marriage between Korean men and foreign women scaled up in the mid-1990s, peaked in the mid-2000s, and diminished since; as a result, multicultural families have become one of the main types of Korean families [1]. Multicultural families can experience compounded difficulties including low socioeconomic status, foreign women's adaptation to Korean society and culture, family conflict due to communication problems, and social discrimination toward marriage migrant women and multicultural families [2]. Since many marriage migrants give birth to children and have to take care of them before they have the chance to adapt to Korean society and culture and their newly formed families, policy and institutional support and programs to help with child-rearing have been provided [3]. Children who were born after international marriages peaked are now entering adolescence, ne- cessitating the preparation of a detailed support strategy to facilitate healthy development of adolescents in multicultural families and to promote positive parent-child relationships.

During early adolescence when puberty starts, emotional agitation and rapid physical and sexual maturation result in negative emotions such as sadness and irritation, and adolescents find themselves in conflict situations with parents more frequently due to reduced closeness with their parents and their sensitive reactions to parents' involvement in their studies or daily lives [4]. Adolescents in multicultural families experience decreased self-esteem and identity crises due to social discrimination and exclusion as a result of not being acknowledged as Korean and experience difficulty in forming relationships with peers [5], which makes accomplishing developmental tasks difficult. Early adolescents desire to have frequent conversations with their parents and to be comforted by them to overcome difficulties and conflicts [6]. Adolescents in multicultural families showed higher self-esteem and more stable identity when they had closer relationships with their 
mothers [7], and adolescents reported higher life satisfaction when they perceived higher family support [8].

In South Korean society, the responsibility of child-rearing is perceived to belong to mothers rather than fathers, meaning that mothers experience more psychological responsibility and burden than fathers [9]. Mothers born in other countries in multicultural families can be treated as "foreigners" by their children and may have less control of family matters than fathers, making it difficult for mothers to establish authority and discipline [10]. Mothers in multicultural families are often isolated and unable to form natural relationships with other mothers, share child-rearing experiences, or receive information. In the National Survey of Multicultural Families conducted by the Ministry of Gender Equality and Family in Korea [2], 17.3\% of marriage migrants reported that they experienced difficulty in participating in school activities for parents, and $33.9 \%$ reported that they did not have anyone with whom to discuss child education

Entry into adolescence can be a confusing and difficult process for both mothers and children. Mothers are faced with the need to understand the physical and psychological changes their children experience, establish a new relationship with their children, and change their child-rearing attitudes [9]. Migrant mothers in multicultural families face a different situation than what Korean mothers face since migrant mothers face the additional burden of raising children in a foreign culture and environment while helping their children navigate the changes they experience while entering adolescence. A positive parent-child relationship is important for the healthy psychological and emotional development of adolescents in multicultural families, but qualitative studies that comprehensively explore mothers' child-rearing processes during the developmental changes of adolescence are rare. Therefore, it is necessary to establish foundational material for interventions to promote desirable child-rearing practices and relationship-building by exploring the child-rearing experiences of mothers in multicultural families in order to help mothers in multicultural families in South Korea cope with the developmental changes in their children during early adolescence and raise children in a healthy manner.

This study, using qualitative content analysis [11] to analyze data and interpret meaning, aimed to explore the experiences of mothers in multicultural families raising early adolescents in-depth and to interpret the meaning of those experiences. Qualitative content analysis is a research method that identifies themes or patterns in the data through the coding process, which is used to systematically categorize data, and interprets the content of the data [12]. In order to construct a model that describes a phenomenon conceptually, the research proceeds through the preparation, organizing, and reporting phases. Two approaches exist: deductive and inductive analytic processes [13]. The inductive approach is used when there is an insufficient number of previous studies on the phenomenon of interest or the existing studies are fragmented [13]; therefore, it is appropriate for the study of adolescent child-rearing in multicultural families since knowledge is not integrated and the topic has not been actively researched. It is also useful for extracting general and comprehensive categories from specific phenomena experienced by mothers who have early adolescent children in multicultural families.

Therefore, using qualitative content analysis, this study aimed to explore in-depth the child-rearing experiences of mothers with early adolescent children in multicultural families in South Korea, to understand the meaning of those experiences, and to describe that meaning.

\section{Purpose}

The aim of this study was to explore and describe the childrearing experiences of mothers in multicultural families with early adolescent children through qualitative content analysis. The research question was: "What do mothers in multicultural families with early adolescent children experience while raising children in South Korea?".

\section{METHODS}

Ethics statement: This study was approved by the Institutional Review Board of Dongyang University (No. 1041495-201912HR-01-01). Informed consent was obtained from the participants.

\section{Study Design}

This qualitative study inductively analyzed in-depth interviews with mothers in multicultural families with early adolescent children in South Korea about their child-rearing experiences, using qualitative content analysis [11].

\section{Study Participants}

The study participants were six mothers in multicultural families with early adolescent children. Potential participants were migrant women who had married Korean men, were living in South Korea, could communicate in Korean, and had one or more early adolescent children from fifth to eighth grade. In order to collect rich data on individual experiences about each question, women who could directly describe their experiences or actively communicate meaning in Korean were 
recruited through a Multicultural Family Support Center in Gyeongbuk. Participants were first sampled purposively, and then the sampling process was gradually changed to reflect theoretical aims. Women were included in the study as participants when they provided written consent to voluntarily participate in the study.

The demographic characteristics of the study participants are demonstrated in Table 1 . The participants' countries of birth were the Philippines (two participants), Vietnam (three participants), and Japan (one participant). Four were in their $30 \mathrm{~s}$, and two were in their 40s. One had graduated from high school, four had graduated from university, and one had completed graduate school. All participants except one were employed.

\section{Ethical Considerations and Data Collection}

To protect the study participants, the study received approval (No. 1041495-201912-HR-01-01) from Dongyang University Institutional Review Board (IRB). The study purpose and procedure were explained to the recruited women, who were also informed that they would participate in recorded individual interviews, all information would be anonymous, confidentiality was guaranteed, and data would be discarded after research completion. Participants were also informed that they did not have to participate if they did not want to, that they could discontinue participation at any time during the interview, and that they could request their data to be discarded even after the interview. In-depth interviews took place after obtaining written informed consent for voluntary participation in the study, and participants received a gift for their participation.

Data collection took place from January 14 to July 7, 2020. In a pre-interview that lasted for 20-30 minutes, closeness and trust were built with participants, and the time and location for an in-depth interview were determined. The first interview took place in an independent and quiet space without disruptions (home, café, etc.). Since COVID-19 made in-per- son contact difficult, the second interview was done over the phone. The conversation started with questions about daily life, and when the participants relaxed and started to feel comfortable, more in-depth questions were asked. The researcher actively listened to the participants during the interview and asked relevant questions about the participants' stories.

The interview questions were structured based on previous studies, the relevant literature, and the researcher's previous experience with the goal of encouraging participants to talk about their child-rearing experiences. The main question was: "Could you tell me about your child-rearing experiences with your adolescent child?" Supporting questions were: "Could you tell me about the changes you experienced while raising your adolescent child?", "Could you tell me about the difficulties you experienced while raising your adolescent child?", and "Could you tell me about what you did when you faced difficulties raising your adolescent child?"

The overall atmosphere, emotional responses, and non-verbal communications were observed during the interview. Each participant took part in one or two interviews for 1-2 hours, for a total of 2-3 hours. The interviews were recorded and transcribed immediately after the interviews with notes on observations and remarks from the researcher. Data collection was concluded when no more new information appeared in the data and similar information was repeated, leading to the determination of data saturation. The collected data were assigned a number instead of the participant's name to prevent exposure of personal information, and the transcripts were kept on a computer with a two-step identification password to prevent access by anyone other than the researcher.

\section{Data Analysis}

Data analysis was conducted simultaneously with data collection, following the inductive approach of qualitative content analysis [13].

In the preparation phase, the recorded interviews were listened to repeatedly and transcribed. The researcher studied

Table 1. Sociodemographic Characteristics of Participants $(N=6)$

\begin{tabular}{|c|c|c|c|c|c|c|}
\hline ID & Nationality & Age (year) & Educational level & Migration year & Employment & Number of children \\
\hline 1 & Philippines & 42 & University & 2007 & Yes & 3 \\
\hline 2 & Vietnam & 34 & University & 2006 & Yes & 2 \\
\hline 3 & Japan & 48 & Graduate school & 2005 & Yes & 2 \\
\hline 4 & Philippines & 36 & University & 2012 & Yes & 4 \\
\hline 5 & Vietnam & 35 & University & 2006 & Yes & 3 \\
\hline 6 & Vietnam & 35 & High school & 2005 & No & 1 \\
\hline
\end{tabular}


the data overall by repeatedly reading the transcripts. Considering that the unit of analysis should be large enough to review the whole phenomenon, but not too broad to be able to consider the context [11], sentences that expressed the childrearing experiences of mothers in multicultural families with early adolescent children were selected as the unit of analysis.

In the organizing phase, open coding was done, and meaningful statements were extracted after understanding the mothers' child-rearing experiences by repeatedly reading each unit of analysis. Important information was recorded as general and abstract statements in the coding sheets, and similar content was grouped to create sub-categories that were abstracted to a higher level. The abstracted sub-categories were grouped by similarity to create categories that were abstracted to an even higher level, and each category was described using words that characterized the category.

In the final reporting phase, categories were suggested.

\section{Trustworthiness of the Study and Reflexivity}

To ensure the trustworthiness of the study, efforts were made to increase credibility, fittingness, auditability, and confirmability [14]. In order to increase credibility, open-ended questions were asked so that participants could express their experiences in their own words, the interview content was confirmed in the next interview, categories were compared to the original data, and whether the analysis results reflected participants' experiences properly was discussed with colleagues. To increase fittingness, concepts were extracted from participants' experiences, interviews and observations were conducted until theoretical saturation was reached, and additional explanations about child-rearing in multicultural families from the staff in Multicultural Family Support Center were taken into account. To increase auditability, participants' words were quoted directly so the readers could review the results of the study, and the results from collecting and ana- lyzing data were recorded in detail. To increase confirmability, the researcher tried to explore the child-rearing process without subjective judgements or pre-existing stereotypes in the process of conducting interviews and analyzing data.

Moreover, following the inductive approach checklist by study phase [15], the preparation phase (including data collection and sample extraction), the organizing phase (including categorization, abstraction, data interpretation, and representativeness), and the reporting phase (including presentation of results and the analytic process) were conducted and described in detail.

The researchers are professors in pediatric nursing who have an interest in child and adolescent development and the relationship-building process between parents and children and who have been conducting research while exploring the relevant literature. The researchers are also interested in childrearing and parent education in multicultural families, and one researcher has participated as a lecturer in health promotion education at the Multicultural Family Support Center. The academic literature and non-academic data on parentchild relationships and multicultural families were reviewed to improve theoretical sensitivity, and the research was conducted with careful reference to qualitative research methods.

\section{RESULTS}

Forty-three meaningful statements, nine subcategories, and four categories that characterized the child-rearing experience of mothers in multicultural families with early adolescent children in South Korea were extracted. The four categories extracted were: "separation between myself and others," "distance between myself and my adolescent child," "making efforts to bridge the gap between myself and others," and "trying to connect with my adolescent child closely." The results are presented in detail in Table 2.

Table 2. Categories of Child-rearing Experiences of Mothers with Early Adolescents in Korean Multicultural Families

\begin{tabular}{ll}
\hline Categories & \multicolumn{1}{c}{ Subcategories } \\
\hline Separation between myself and others & - Enduring the burden of child-rearing by myself \\
Distance between myself and my adolescent child & - Suffering from discrimination \\
& $\begin{array}{l}\text { - Lack of qualification as a mother and feeling sorry for my child } \\
\text { - The barrier between myself and my child }\end{array}$ \\
Making efforts to bridge the gap between myself and others & - My child moving further away from me during puberty \\
& - Acting like a Korean \\
Trying to connect with my adolescent child closely & - Maintaining my culture \\
& - Catching up with my adolescent child \\
\hline
\end{tabular}




\section{Category: Separation between Myself and Others}

1) Subcategory: Enduring the burden of child-rearing by myself

The study participants had to take care of children by themselves without help since their birth family members were far away and their husbands were not interested in child-rearing. Participants had difficulty understanding at hospitals when their children were sick or in schools when they visited to participate in parent meetings since their Korean was not fluent. They also experienced difficulties since their verbal expressions were clumsy. They were surprised about the educationfocused and highly competitive atmosphere in South Korea. It was hard for them to help their children with spelling when the children were younger, and as the children grew older, mothers felt burdened in helping children with their studies due to the level of the study materials.

Nobody, nobody. My mother can't come here. I am doing it by myself. I am rearing my boy by myself. (Participant 6)

My children's textbooks, for example the social studies textbook, are different from what I learned in Vietnam, so when I look at it, I don't know what it's talking about. (Participant 2)

\section{2) Subcategory: Suffering from discrimination}

The participants felt that parent-child roles and the expectations of children were different in South Korea from those in their country of birth. They were not confident and worried that they were raising their children wrong. They were also scared that their Korean neighbors would criticize or report their discipline of their children as child abuse. They also felt that their culture was not respected, as their husband's family members told them not to teach children their mother tongue or speak it at home so that their children would learn Korean well. The participants kept their distance from other people by not attending parent meetings or not interacting with other parents so that they would not be belittled by people who look at them differently due to their appearance or speech, which differed from those of Koreans, and who had prejudices or stereotypes towards their home country.

When I visited the school,(another child's mother) asked "Why did you not come with the child's dad? Why did he not come with?" She asked why the child's dad did not come with me. She also asked directly "Did you understand what the teacher said?", which hurt my feelings. And there are things to fill out. She said "Do you know how to fill it out? Do you understand? Can you write?" That made me feel bad. So, that time I felt that multicultural families are different from normal families. (Sad voice, tears in her eyes.) (Participant 1)

A few years ago, the aunts forced me not to teach the child Vietnamese, worrying that the child would learn Vietnamese. They also said that if you go out like that, you will look like a foreigner. They are embarrassed to say "multicultural family." They often said that. They thought that I would be belittled or that I was embarrassing because I am a foreigner. That's how I felt. So, I don't keep in touch with the aunts, and I don't really do anything, especially. (Participant 6)

\section{Category: Distance between Myself and My Adoles- cent Child}

\section{1) Subcategory: Lack of qualification as a mother and feeling sorry for my child}

The study participants were hurt by their children experiencing bullying and teasing from peers for being from a multicultural family and having difficulties in their studies because they were not able to help their children with studying due to a lack of fluency in Korean. They were still worried that their children would be hurt by bullying and teasing. The participants felt that the discrimination and difficulty in learning experienced by their children were their fault, and felt sorry toward their children because they were not able to care for their children like other Korean mothers do.

I want to teach them, but I really could not figure it out. I am not enough, and I felt sorry, very sorry toward my children because I should be able to teach them, but I could not. (Participant 2)

Friends don't play with her because her mom is from the Philippines, because of her skin color. So, my oldest daughter, whenever there is a parent meeting or counseling, she picks out an outfit from my closet, "Mom, you have to look pretty". "Mom, you should wear this tomorrow. You have to look pretty." When I look at her diary, it's because her friends tease her. It's because of that, so it was really difficult. It was really difficult because my confidence dropped. I often thought, ** is right. Would ** be happier if she didn't have a Filipina mom? I thought about that. A lot. (Participant 4)

\section{2) Subcategory: The barrier between myself and my child}

The study participants experienced difficulties communicating with their children due to the language barrier. They regretted that they did not teach their native language to their children. They experienced their children not wanting to let it be known that their mother is a foreigner and that their family 
is multicultural. They were hurt by their children belittling them for not being able to speak Korean or resenting them for being bullied by their peers about their mother being a foreigner. The participants especially felt sad and distanced by their children not being interested in their mothers' language and culture, thinking they are Korean and not like their foreign mothers, and being closer with the father.

When a friend comes over, my child tells me not to speak Japanese. There were times my child said, "I don't like it when you speak Japanese (when friends are over)." Last year, in fifth grade. When I speak Korean, my pronunciation is not good, so my child said I shouldn't speak Korean. My child once said that it would be good if mom was not home when friends are over. (Participant 3 )

When we go out somewhere, my son always walks in front. He just talks with his dad, talking about important things, education, about how dad worked hard and earned money in the past. My son also talks about his school life. My husband and oldest child seem to be good, talking just between themselves because they are both guys. My son wants to talk, but he might think "Can I talk with mom since she is from the Philippines?" I think he could think that way. (Participant 1)

\section{3) Subcategory: My child moving further away from me during puberty}

The study participants felt that their children were different as they entered puberty and were surprised about differences in perceptions about puberty and attitude toward pubescent children in South Korea compared to those in their home countries. Children wanted to be alone, became close with their friends, became stubborn, and experienced growth beyond their parents' control. Due to the difficulties that participants had experienced communicating with their children due to the language barrier, they worried that they would not be able to notice when there are issues with their children, thinking about the experiences of their children being bullied or teased, as communication with children was even less frequent due to puberty.

She wants to be alone all the time. She was good with friends until fifth and sixth grade. I went to counseling and heard from the teacher that she only was good with friends. She needs to go to middle school now. It could become worse in middle school. seventh, eighth, and ninth grade. It becomes more difficult. (Participant 1 )

In the Philippines, a daughter becomes closer with her mom when puberty starts. Because it's a girl child. They want to have the same hobbies and the same things as their mothers. But my daughter became more and more distant when puberty came. Here, they want to be alone. They want everything their way. I'm most worried about ** keeping secrets from me. There is something, and she doesn't tell me. Something that's really hard, that's really hurtful. That worries me the most. I want to stay close, but she keeps moving away. I'm scared that there will be a secret kept from me. (Participant 4)

\section{Category: Making Efforts to Bridge the Gap between Myself and Others}

\section{1) Subcategory: Acting like a Korean}

The study participants tried to adapt to life in South Korea to support and protect their children while watching them grow. The participants tried to be responsible for their own decision to marry a Korean person and live in South Korea. The participants thought that to raise their children well, they must adapt well to the Korean lifestyle, and to do so, they have to speak Korean well. Since children need help from their mothers to learn Korean, the participants made efforts to learn Korean first, and they deemed fluency in Korean to be a marker of being Korean. The participants were proud of being good at Korean, and they felt their children were also proud of their mothers being good at Korean. The participants actively sought help from others to adapt to Korean society and received help from their children's school or local child centers for issues they could not resolve on their own.

I think Korean people think differently. Since I am a Filipina, but I have to live in South Korea, I have to know Korean culture and food, work like Korean mothers, and know what children are like. Isn't that right? I have to become South Korean for my children. (Participant 1)

Sometimes, my child's friend comes with us. I drive and drop the friend off from time to time. The friend said, "Auntie, I really didn't know you were Vietnamese." So, I asked, "Why not?", "Auntie is just like a Korean person. How come you are so good at Korean?", the friend said so. (laughs) Everything is possible when you work hard. You can't tell that ${ }^{* *}$ is from a multicultural family at all. **'s Korean is very good. I am happy that I hear these things. I think this is the best thing. (Participant 6)

\section{2) Subcategory: Maintaining my culture}

The study participants maintained their identity from their place of birth, and when they acquired Korean nationality, they identified as having dual citizenship. They made efforts to raise awareness about their native culture and multiculturalism through their children's school or the Multicultural 
Family Support Center. They continued to interact with people from their home country or other multicultural families and helped each other.

Since I have dual citizenship, I don't think I'm completely Korean. I was born in Vietnam, but since I am going to be living in Korea, I must be Korean. I don't think this way. I consider myself as a foreigner. But I am not less confident because I am a foreigner because it's been a long time that I lived here, I am almost completely adapted. That's why. I don't know how other people think, but I live with these thoughts. (Participant 2)

I talk with Vietnamese friends. I call them. We have a group that meets once every two months. There are Vietnamese people and people from other countries too. I visited a friend's house not too long ago with my children. (Participant 5)

\section{Category: Trying to Connect with My Adolescent Child Closely}

\section{1) Subcategory: Catching up with my adolescent child}

The study participants understood that puberty is a natural change, that their pubescent children's experiences are different from theirs due to differences in the situation and environment, and that their children wanting to be alone and becoming closer to their friends are characteristics of puberty. Changing their style of discipline, they tried to solve problems through conversations, to trust and acknowledge their children, and to allow independence. They wanted to become closer to their children, sought ways to spend time together to avoid growing apart, and tried to solve conflicts by talking.

I try not to judge. If I give the child a hard time, he won't even tell me the test score next time. He might lie, so I just ask what he thinks about his score. Even if the score is good, I ask about it. If he says he is satisfied, I just reply "Okay, you must have worked hard." I try not to judge with those things. I'm trying to do that. (Participant 3)

I think it's just the moment. The stress for me, it's just a moment. My children aren't having a hard time because of puberty, and it's not hard for me that my children are going through puberty. It's just that since their personality changes, they feel confused, their personality changes, and it's just a moment. Some kids don't listen to their parents and leave the house. My child does not do that. My child also wants to go to friends' houses. My child asked, "Why can't I go?" I told my child, "This is South Korea. If this were Vietnam, I would know about the culture, but I'm a foreigner. If you go and something happens, what if it becomes difficult for me? This is South Korea, and I still don't understand whether you can sleep over or not according to Korean culture." I explain. I say, "If you want to get together with your friends, clean up your room and bring your friends here. You guys can sleep here." (Participant 5)

\section{2) Subcategory: Connecting my child to my culture}

The study participants experienced their children being accustomed to Korean society and culture and regarding themselves as Korean, while taking an interest in the culture of their mother's country and learning their mother's native language naturally, and felt that their native culture and Korean culture connected in their children. The participants also felt that their children connected them to Korea by accepting them as who they are and using their native language. The participants wanted their children to understand them, made efforts to teach children their native language and culture, and gave children the opportunity to experience their native country by bringing their children along whenever they visited and allowing them to meet and communicate with members of their mothers' families. The participants thought that there was a chance that their children could succeed and develop in their native country, which is in a different stage developmentally, planned their own and their children's future, and discussed these topics with their children. The participants wanted their children to be bilingual, using the strength of multicultural families and becoming fluent in both Korean and their mother's native tongue, and taught children their native tongue.

I'm Filipina. When I go to the Philippines, visit with my children, or go there for fun, I want to tell cousins or neighbors. I want to teach that to my children. We can go to the Philippines anytime. We can have conversations in the Philippines. I also teach my children my culture. "In the Philippines, we do it this way. In Korea, it's that way." I teach them like this. My daughter has been saying she wants to go to the Philippines recently. I told my daughter, "If you want to go to the Philippines, you first have to learn the language, right? Like mom. When I came to Korea, I didn't know any Korean and had a very hard time." (Participant 1)

My adolescent child could go study there or visit cousins. So, in these cases, my child has to know Vietnamese. I started teaching my child two years ago. Since we go every two years, I think my child knows quite a lot naturally. We go for my mother's death anniversary and the new year every other year. When we visited this time, my child used a lot of Vietnamese. He understands everything and can speak in Vietnamese. Writing is difficult, 
but he can speak. If I teach him diligently at home, he can learn faster. If he can speak Vietnamese well, I want to send him there for studies. (laughs) There are good middle schools and high schools in Vietnam. There are also international schools. (Participant 6)

\section{DISCUSSION}

This study extracted four categories by using qualitative content analysis with in-depth interviews conducted to understand the meaning of child-rearing experiences of mothers in multicultural families with early adolescent children in South Korea.

Study participants faced the burden of child-rearing on their own and were distanced from other people, resulting in the category of "separation between myself and others." Participants experienced communication issues in their daily lives with children due to their Korean level and were not confident on how to raise children in South Korean culture, which is different from their own. In a previous study [16], marriage migrant women also experienced conflict due to differences in culture and value systems related to child-rearing and felt inferior about not being able to perform the mother's role well. In this study, participants had to take care of children on their own without help from family members in their native country who were far away and from husbands who were not interested in child-rearing. Oh and Kim [10] also reported that conflicts due to the patriarchal family culture and indifferent husbands made child-rearing difficult for mothers in multicultural families.

The participants also felt that their language and culture were not respected when their husband's family members told them not to teach their children their native language. They maintained a distance from other people to avoid getting hurt by people who discriminated based on their appearance and speech or who had prejudices against their home country. Discrimination against mothers in multicultural families in South Korea results in mothers withdrawing psychosocially, making interpersonal relationships even more difficult [17]. The phenomenon of mothers in multicultural families withdrawing after experiencing discrimination due to being a foreigner and not forming relationships with other people is expressed as a life of isolation and alienation [10]. The lack of social connections and a withdrawn lifestyle lead to conflict in child-rearing and confusion about their role as a parent. Receiving help from a support system strengthens mothers' determination and ability to overcome problems and facilitates a positive parenting role [18]. Therefore, it is necessary to foster a more active support system of mothers in multicultural families for ideal child-rearing. It is also necessary to find ways to increase family support and strengthen social support from schools, neighbors, and Multicultural Family Support Centers.

The study participants distanced themselves from their children, feeling inadequate as a mother and feeling sorry toward their children, resulting in the category of "distance between myself and my adolescent child." Participants felt sorry because their children were bullied and teased for having foreign mothers and because they thought their children had difficulties studying due to their Korean being poor. In a previous study of Chinese women who migrated to South Korea [17], participants were worried that because they were migrants, their children would be discriminated against in South Korea and would not develop normally. They perceived their own inadequacies of being a foreigner and not speaking Korean fluently to be the cause of their children's problems in studying, and husbands and husbands' family members in multicultural families often view children's problems as being issues in the mother's childcare rather than the responsibility of both parents. Mothers experience negative emotions such as feeling guilty and sorry [18].

Participants experienced difficulties communicating with their children due to the language barrier and felt badly about children belittling their mothers who did not speak Korean well and being closer to their fathers. In a previous study [16], marriage migrant women had difficulties communicating with children and felt sorry toward their children for not being able to take care of them as well as Korean mothers. Migrant mothers' guilt and lack of confidence in their role as a parent become barriers to providing the psychological support necessary for children's emotional stability [18]. As children grow, the gap between the levels at which Korean is used and understood by mothers and adolescent children grows as well. This gap can make conversations and communication even more difficult, worsening parent-child conflict [10]. It is necessary for mothers in multicultural families to overcome conflicts and maintain closeness with adolescent children through conversation and communication. The confidence of adolescent children in multicultural families was found to be higher when they were close with their mothers [7].

The participants felt that they were growing apart from their children as their children entered puberty, and were perplexed by the cultural differences in changes associated with puberty. Adolescence is characterized by rapid physical growth, cognitive development, emotional agitation, and psychological conflicts [19]. Adolescence connects the two different worlds of childhood and adulthood. Adolescents in multicultural or immigrant families also form a connection between the culture of their parents' native countries and the culture of their country of residence, resulting in them con- 
necting four different worlds (childhood, adulthood, their parents' native country, and their country of residence) [20]. In this study, children did not want to tell their friends that their mother is a foreigner and that they are from a multicultural family. Adolescents in multicultural families in South Korea regard themselves as Korean, but they are not recognized as Korean by other people, leading their identity to be somewhere between a native and an immigrant [5]. With the increasing number of children in multicultural families who are entering adolescence in South Korea [7], it is necessary to prepare detailed measures for and to take a deep interest in the identity formation of adolescents in multicultural families and their psychosocial adjustment.

The study participants tried to maintain their native culture while striving to adapt to Korean culture, resulting in the category of "making efforts to bridge the gap between myself and others." Participants tried to adapt to life in South Korea for their children as children grew and had more demands, and tried to learn Korean. A previous study [10] also reported that out of guilt toward their children, mothers in multicultural families tried to be less dependent on their husbands, learn Korean, recognize their independent roles, and seek new changes to protect their children. However, it was hard for them to become Korean mothers when they were not Korean. As expressed by a migrant mother who said that she would live proudly telling people about her home country [18], mothers should maintain their own identity and become less passive to establish a good relationship with their children.

In this study, participants made efforts to become fluent in Korean, just like Korean people, but also tried to maintain and tell others about their own native culture. In a previous study of Chinese immigrant women in South Korea [17], participants maintained their identity as Chinese while joining Korean society and thus became mothers who integrated the two cultures in South Korea. Maintenance of their native culture by mothers in multicultural families and their attitudes towards accepting the new Korean culture are related to adolescents' school adaptation [21]. Attitudes toward cultural adaptation refer to the level at which people maintain their own unique culture and identity and the level at which they accept the norms and culture of the mainstream society and are categorized into four types: separation (when the level of maintaining their own unique culture is high), assimilation (when the level of accepting the mainstream culture is high), marginalization (when both levels are low), and integration (when both levels are high) [22]. When mothers in multicultural families maintained their own native culture and were simultaneously open and receptive toward Korean culture, children perceived that they received a lot of support from their family and had high life satisfaction. This associa- tion was maintained steadily from grade 6 to grade 8 [8]. Therefore, helping mothers in multicultural families to have an integrated attitude toward cultural adaptation will be effective for facilitating adolescent children's psychosocial adjustment.

The study participants understood the changes in their pubescent children, tried to become closer to their children, taught their children their native language, gave their children the opportunity to experience their native culture, and tried to connect their children to their native culture, resulting in the category of "trying to connect with my adolescent child closely." In a previous study of Korean mothers [9], mothers re-established their relationship with their children by recognizing their adolescent children as independent people and trying to respect their children's choices. Parents and children can grow together when they understand and respect each other. Starting in early adolescence, which coincides with upper elementary school when children's linguistic abilities develop and children become more emotionally sensitive, it is not sufficient to communicate feelings through simple conversations and facial expressions [23]. Language is a very important social interaction tool in our lives and a main feature of a culture; therefore, in order for mothers and children in multicultural families to share complex thoughts and deep emotions and understand each other sufficiently, a common language should be developed. Language is a tool used to transfer a unique culture from one generation to another in multicultural and immigrant families that perpetuates the value and symbolic meaning of the culture [20]. Mothers in multicultural families practicing Korean and helping their children to accept their native language and culture will provide an opportunity for mothers and adolescent children to understand each other and grow together.

The study participants wanted their children to be Korean and strongly connected to their native country at the same time and tried to introduce their native culture to their children. In a previous study conducted a decade ago [23], the motivation for mothers in multicultural families to recognize their children as Korean was their hope for their children to grow up in South Korea without discrimination. They prioritized their children growing up as Korean over their children learning another language, which is a strength of multicultural families. The results of this study represent a change in the cultural adaptation of multicultural families and show that multicultural families aim to integrate and have a positive relationship with mainstream Korean society while maintaining their unique culture and identity, rather than simply assimilating to mainstream society [22].

Since this study sampled mothers in multicultural families residing in a single region and included mothers who spoke 
Korean at a level at which they could speak about their experiences comfortably so that their experiences could be explored through in-depth interviews, there is a limitation in generalizing the results of this study to the experiences of all mothers in multicultural families. The mothers in multicultural families in this study discussed their experiences raising children when they first arrived and got married and did not speak Korean well, but their experiences might be different from those of mothers who still have major difficulties communicating with their children as their children enter adolescence. Future studies should include participants who have limited Korean by working with a researcher who speak the mothers' native language or by using an interpreter during the interviews. By exploring the child-rearing experiences of mothers in multicultural families with early adolescent children in South Korea and their meaning in-depth, this study will provide foundational material for interventions that support ideal childrearing practices and parent-child relationships.

\section{CONCLUSION}

This study explored the child-rearing experiences of mothers in multicultural families with early adolescent children in South Korea with the goal of understanding the meaning of those experiences. By conducting in-depth interviews with six mothers with early adolescent children and analyzing the data using qualitative content analysis, the following categories were extracted: "separation between myself and others," "distance between myself and my adolescent child", "making efforts to bridge the gap between myself and others", and "trying to connect with my adolescent child closely". Mothers in multicultural families faced the burden of child-rearing alone and were distanced from other people. They were also distanced from their children, felt inadequate as mothers, and felt sorry toward their children. However, they also tried to maintain their native culture while adapting to Korean culture. They understood their pubescent children's changes, became closer to their children, taught their children their native language, gave their children the opportunity to experience their native culture, and tried to connect their children to their native culture. Education and support programs that promote good relationships between adolescent children and parents in multicultural families and that reflect the child-rearing experiences of mothers in multicultural families should be implemented.

\section{ORCID}

Sangmi Lee Hyun Young Koo

https://orcid.org/0000-0002-7611-670X https://orcid.org/0000-0001-5848-2143

\section{Authors' contribution}

Conceptualization: all authors; Data collection: Sangmi Lee; Formal analysis: all authors; Writing-original draft, Writingreview and editing: all authors; Final approval of published version: all authors.

\section{Conflict of interest}

Hyun Young Koo has been the editor-in-chief of Child Health Nursing Research since January 2018, but had no role in the decision to publish this manuscript. No existing or potential conflict of interest relevant to this article was reported.

\section{Funding}

This study was supported by the research fund of Dongyang University in 2019.

\section{Data availability}

Please contact the corresponding author for data availability.

\section{Acknowledgements}

None.

\section{REFERENCES}

1. Ministry of Gender Equality and Family. International marriages status [Internet]. Daejeon: Statistics Korea; 2020 [cited 2021 February 20]. Available from:

http://www.index.go.kr/potal/main/EachDtlPageDetail.do?idx cd $=2430$

2. Choi YJ, Kim IS, Sun BY, Dong JY, Jung HS, Yang GI, et al. 2018 National multicultural family survey report. Survey Report. Seoul: Ministry of Gender Equality and Family; 2019. Report No.: 111383000-000384-12.

3. Ministry of Gender Equality and Family. 2020 Implementation plan for multicultural family policy [Internet]. Seoul: Ministry of Gender Equality and Family; 2020 [cited 2021 February 22]. Available from:

http://www.mogef.go.kr/mp/pcd/mp_pcd_s001d.do?mid=plc 503\&bbtSn=704861

4. Kim AY, Park BK, Kim SJ, Rhee SH, Do HS. A qualitative study on experiences of parenthood of mothers with adolescents. Korean Journal of Youth Studies. 2017;24(8):161-193. https://doi.org/10.21509/KJYS.2017.08.24.8.161

5. Choi Y, Lee J, Kang S. A phenomenological study on the daily experience of multicultural families adolescents. Journal of Humani- 
ties and Social Science (HSS21). 2020;11(1):1747-1761.

https://doi.org/10.22143/HSS21.11.1.127

6. So SY, Ahn JY, Yang DH, Kim KM. Parental and adolescent perceptions of transitions during early adolescence: With a focus on the FGI of adolescents and parents. Korea Journal of Youth Counseling. 2014;22(1):247-279. https://doi.org/10.35151/kyci.2014.22.1.011

7. Cha SE, Ryu J. Asian migration background and psychosocial adaptation of adolescents in multicultural families: Migration background, barriers or resources? Korea Journal of Population Studies. 2019;42(3):55-81.

https://doi.org/10.31693/KJPS.2019.09.42.3.55

8. In H. Longitudinal relationships among adolescents' perceived family support, life satisfaction, and mothers' acculturative stress in multicultural families. Korean Journal of Youth Studies. 2017; 24(10):459-482.

https://doi.org/10.21509/KJYS.2017.10.24.10.459

9. Koo HY. Experienes of the development of parent-adolescent relationships among Korean mothers. Child Health Nursing Research. 2019;25(3):355-366. https://doi.org/10.4094/chnr.2019.25.3.355

10. Oh OS, Kim SB. Phenomenological approach to child-rearing experiences of mothers from multicultural families. Journal of Family Relations. 2012;17(1):259-278.

11. Graneheim UH, Lundman B. Qualitative content analysis in nursing research: Concepts, procedures and measures to achieve trustworthiness. Nurse Education Today. 2004;24(2):105-112.

https://doi.org/10.1016/j.nedt.2003.10.001

12. Son HM. Understanding and application of qualitative content analysis. Journal of Korean Association for Qualitative Research. 2017;2:56-63.

13. Elo $S$, Kyngäs $H$. The qualitative content analysis process. Journal of Advanced Nursing. 2008;62(1):107-115. https://doi.org/10.1111/j.1365-2648.2007.04569.x

14. Sandelowski M. The problem of rigor in qualitative research. Advances in Nursing Science. 1986;16(2):1-8.
15. Elo S, Kääriäinen M, Kanste O, Pölkki T, Utriainen K, Kyngäs H. Qualitative content analysis: A focus on trustworthiness. SAGE Open. 2014;4(1):1-10. https://doi.org/10.1177/2158244014522633

16. Kim MH. A phenomenological study on parenting experience of marriage migrant women in multicultural families. Korean Journal of Family Social Work. 2019;66:147-180.

https://doi.org/10.16975/kjfsw.2019..66.005

17. Roh EH, Song JE. Grounded theory approach for becoming a mother of Chinese immigrant women in Korea. Journal of the Korean Society of Maternal and Child Health. 2017;21(3):166-175. https://doi.org/10.21896/jksmch.2017.21.3.166

18. Oh OS, Kim SB. Looking into child-rearing experience of mothers from multicultural families through the grounded theory paradigm model. Korean Psychological Journal of Culture and Social Issues. 2012;18(2):235-260.

19. Cho BH, Jung OB, Yoo GH. Human development: Psycho-developmental approach. 2nd ed. Seoul: Kyomoonsa; 2004. p. 118-135.

20. Quinones-Mayo Y, Dempsey P. Finding the bicultural balance: Immigrant Latino mothers raising "American" adolescents. Child Welfare. 2005;84(5):649-667.

21. Ding J, Chin M. The effect of foreign mothers' acculturation on multicultural family adolescents' adaptation of learning activities: Mediating effect of mothers' educational involvement in home, public educational support, and private tutoring. Journal of Family Relations. 2019;24(2):65-84. https://doi.org/10.21321/jfr.24.2.65

22. Sabatier C, Berry JW. The role of family acculturation, parental style, and perceived discrimination in the adaptation of secondgeneration immigrant youth in France and Canada. European Journal of Developmental Psychology. 2008;5(2):159-185. https://doi.org/10.1080/17405620701608739

23. Song MK, Jee SH, Cho EK, Lim YS. A study on the parental experience of a foreign mother in a multicultural family. Korean Journal of Counseling and Psychotherapy. 2008;20(2):497-517. 